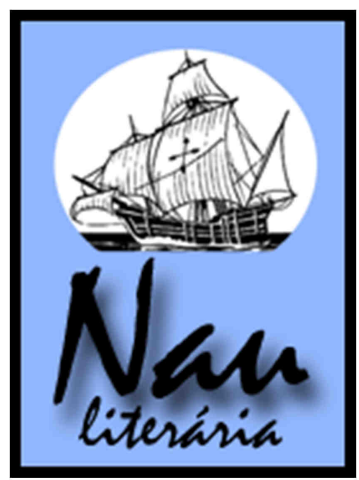

\title{
Mia Couto e sua maneira de emendar, apagar e enfeitar a vida através da literatura
}

\section{Bianca Rodrigues Bratkowski*}

\begin{abstract}
Resumo: O presente ensaio traz uma reflexão acerca do processo criativo do escritor Mia Couto a partir de questões referentes à linguagem, personagens, temas e outros elementos constantes de suas obras.
\end{abstract}

Abstract: This essay shows a reflection on the creative process of the writer Mia Couto from issues relating to language, characters, themes, and other elements contained in his works.

Palavras-chave: Mia Couto; processo criativo; Keywords: Mia Couto; creative process; literature. literatura.

Mia Couto (António Emílio Leite Couto) nasceu na cidade Beira, Moçambique, em 1955. Colaborou com a FRELIMO (Frente de Libertação de Moçambique) e, após a Independência Nacional, dedicou-se a atividades jornalísticas. Além de escritor e professor da Universidade Eduardo Mondlane (UEM), é formado em Biologia e dirige uma empresa que faz estudos de impacto ambiental.

$\mathrm{Na}$ literatura, começou a escrever poemas e publicou seu primeiro livro de poesia, Raiz de orvalho, em 1983. Depois, dois livros de contos: Vozes anoitecidas (1986) e Cada homem é uma raça (1990). Seu primeiro romance foi Terra Sonâmbula, publicado em 1992.

$\mathrm{O}$ autor relata em entrevistas que foi influenciado primeiramente por Luandino Vieira, autor angolano, e por meio deste, conheceu a obra de Guimarães Rosa. Além destes autores, admite que foi muito marcado por Adélia Prado, Guimarães Rosa, Drummond de Andrade, João Cabral de Melo Neto, José Lins do Rego, Manuel Bandeira, entre outros.

Geralmente, pensamos nas influências literárias dos escritores e não nos atemos às outras formas de arte as quais estão expostos. Mia Couto traz essa questão numa entrevista coletiva durante a $12^{\mathrm{a}}$ Jornada Literária de Passo Fundo, reproduzida no site Portal Literal ${ }^{1}$, contando que ele e sua geração foram muito marcados por alguns músicos brasileiros, como Chico Buarque, Caetano Veloso, Gilberto Gil e Milton Nascimento. O que impressionava o

\footnotetext{
* Graduada em Letras pelo Instituto Superior de Educação Equipe (2009). Mestre em Literaturas Portuguesa e Luso-Africanas pela UFRGS (2013).

${ }^{1}$ A referência do site Portal Literal encontra-se no final do artigo.
} 
autor, além da qualidade da música, era a relação da poesia com as canções.

Após o início de Mia Couto pela poesia, esta ficou impregnada nas suas obras, inclusive em sua prosa. O autor assume que nunca saiu "desse universo da poesia", sendo "um poeta infiltrado no mundo da prosa, contando histórias pelo uso da poesia", e que a utiliza "não apenas como gênero literário, mas como um certo modo de olhar, uma sugestão de outra lógica que só pode ser vista por ela" (PRADO, 2011).

Deste modo, a permanência da poesia vai permear toda a sua obra, incluindo romances e contos, e vai resultar em um dos elementos mais marcantes do estilo de Mia Couto. A partir desta linguagem poética na sua prosa, podemos destacar o uso de aliterações como: "Mas Dulcineusa não cede nem concede" (COUTO $1^{2}$, p. 33); "Pois ele, sempre mais sedento que sedentário, não tardava" (COUTO 1, p. 42); "Diz que se ele é diabético, eu sou diabólica" (COUTO 2, p. 9); "Vou sem causa, venho sem coisa" (COUTO 3, p. 96).

A inserção de metáforas e comparações torna-se, também, algo constante na prosa de Mia Couto, como podemos perceber nos seguintes exemplos: "Palavras que apertam tanto quanto o entrecruzar de braços das mulheres que nos esperam" (COUTO 1, p. 26); "Fiquei com o corpo de minha mãe encostando uma leveza no meu peito, semelhando uma folha tombando do imbondeiro" (COUTO 4, p. 49); "O seu coração tinha mãos fracas: tudo o que ele amava acabava escorregando no nada" (COUTO 4, p. 140); "Falar bem é um perfume que ela gosta de usar, mas que ele não lhe ofereceu" (COUTO 2, p. 99) "Ela se separaria em duas como um fruto que se esgarça: o seu corpo era a polpa; o caroço era a alma" (COUTO 3, p. 168).

Para Calvino, semelhantemente, essa fronteira das distinções de gêneros pode ser flexível: "Estou convencido de que escrever prosa em nada difere do escrever poesia; em ambos os casos, trata-se da busca de uma expressão necessária, única, densa, concisa, memorável" (2010, p. 61). Deslocando, assim, a ideia de fixas delimitações entre os gêneros.

Além da poesia inserida na sua prosa, Mia Couto utiliza uma linguagem bastante peculiar, muitas vezes conjugando as palavras, do que resultam novas expressões, inventando novas palavras, mudando as classes gramaticais delas, ou, ainda, empregando prefixos de forma incomum.

Para exemplificar a junção de palavras, temos: "Ou provoquentes, como diria o Avô" (COUTO 1, p. 211); “A tarefa era simples [...] eu iria à casa grande e espiolharia o que estava no quarto da portuguesa" (COUTO 3, p. 129); "essas mulheres curvilindas despertando febres"

\footnotetext{
${ }^{2}$ Para simplificar as referências nas citações dos livros de Mia Couto, será incluída uma numeração sequencial pela ordem em que aparecem no texto. No final do artigo, encontram-se as referências completas.
} 
(COUTO 5, p. 40); "Ele que era um brutamonstro se diminuíra uns tantos tamanhos" (COUTO 5, p. 122); "Depois seus olhos lusco-focaram: havia uma rede cobrindo as paredes do buraco" (COUTO 6, p. 64).

Quanto ao emprego inusitado dos prefixos: “A arma esquecida, ao lado, tornada em inutensílio" (COUTO 5. p. 110); "E se ele escorregar com alguma dessas inavergonhadas?" (COUTO 7, p. 87); "Que o viajante desaparece é em areia imovediça” (COUTO 7, p. 176); "A morte do português se mantinha assunto multiversivo, tema de serões e fogueiras" (COUTO 6, p. 144).

E, ainda, em relação à alteração de classes gramaticais: "E logo a voz da mãe, lamparinando o fundo do corredor" (COUTO 5, p. 15); "Eu queria era pequeninar tristeza" (COUTO 4, p. 49).

A partir destes trechos, podemos perceber quão rica é a linguagem empregada por Mia Couto e pensarmos em seu processo de criação como uma tarefa minuciosa, pois o autor preocupa-se com as palavras e os diferentes sentidos despertados por ela.

Suas obras, embora escritas em língua portuguesa, não deixam de incorporar vocábulos africanos, cujos significados vêm esclarecidos em notas de rodapé ou em um glossário no final do livro. Ao contrário de interferir na leitura daqueles que desconhecem as diversas línguas africanas, essa mescla proporciona ao leitor um aprofundamento no microcosmo da narrativa, fazendo-o "viver" aquelas histórias de maneira intensa.

Outro fator que contribui para tal fruição é a presença da oralidade nas obras de Mia Couto, visto que as palavras

se sobrecarregam do peso com que as culturas africanas sempre as envolveram, já que, em tais comunidades, falar nunca foi um gesto gratuito, mas uma forma de manter ativa a cadeia da força vital. Por isso mesmo elas são o agente da transformação que tornará o futuro algo melhor.

(PADILHA, 2002, p. 247)

Assim, para os africanos, a palavra ganha uma importância ainda maior, cercada de diferentes significações, "um mais além de si mesma, ela conserva o saber e seu sabor" (PADILHA, 2002, p. 250).

A oralidade junta-se à escrita para acrescentar riqueza aos textos literários, visto que, segundo B. Abdala Junior, a "criatividade linguística é maior na modalidade oral, mais rica em imagens que a aproxima do conjunto cultural" (2007, p. 139). E, por ser um elemento primordial da literatura africana, ela vêm carregada de outros significados, como por exemplo, a transmissão de crenças e tradições. Isto é, 
Se a escrita imortaliza o seu sujeito, a oralidade sagra o seu, conferindo-lhe um peso extraordinário no corpo social. Geralmente os senhores do dito são os "mais velhos" do grupo, não só pela idade, mas pelo papel que nele exercem. A eles cabe ordenar o caos, mantendo a identidade clânica, transmitindo os mistérios da iniciação, enfim, impedindo o esfacelamento da alteridade e/ou a morte dos mitos. (PADILHA, 2002, p. 264)

Essa oralidade, que resgata tradições e perpassa gerações, faz parte da vivência de Mia Couto - o escritor afirma em entrevistas que sua mãe era uma grande contadora de histórias e vai tornar-se elemento constante em suas narrativas.

Após ressaltarmos o trabalho do autor com a linguagem, é necessário pensarmos no processo de tradução que é realizado em suas obras. T. S. Eliot diz que "os textos em prosa têm um significado em suas próprias línguas que se perde na tradução; mas todos sentimos que perdemos muito menos ao lermos uma novela traduzida do que um poema vertido de outro idioma" (1972, p. 29 - 30).

Eliot afirma que há uma perda maior na tradução da poesia em relação a prosa, porém essa dificuldade na tradução ocorre tanto na poesia de Mia Couto, quanto em suas narrativas. Devido à linguagem poética, à oralidade, aos neologismos e aos vocábulos africanos inseridos na sua prosa, torna-se um trabalho árduo a tradução de seus textos e vai ocasionar alguns prejuízos. Entretanto, mesmo com essas dificuldades, suas obras já foram traduzidas para diversas línguas, tais como alemão, francês, espanhol, catalão, inglês e italiano.

Segundo Eliot, é "mais fácil pensar do que sentir numa língua estrangeira”, as pessoas podem "apenas expressar seus sentimentos numa nova língua [...] mas um sentimento ou uma emoção expressos numa língua diferente não são o mesmo sentimento nem a mesma emoção" (1972, p. 30). Aproximando isso à obra de Mia Couto, somos levados a concordar com Eliot, principalmente por dois motivos.

O primeiro é referente à leitura de escritas engajadas, como são as produções de Mia Couto, juntando-se a isso o problema da tradução. O leitor, ao se deparar com alguma das narrativas do autor, deveria ter, no mínimo, uma noção do contexto político, econômico e cultural de Moçambique. Isso não significa que o leitor não entenderia a obra, mas teria uma compreensão limitada e, consequentemente, o aproveitamento ou deleite deste seria menor.

No Brasil, acreditamos que esta compreensão é razoavelmente boa e podemos pensar como uma das razões o nosso passado colonial, pois por termos também sofrido a colonização, temos uma visão mais clara deste processo de reconstrução da nação que Moçambique está passando atualmente. Acrescenta-se a isso, positivamente, o fato de que a tradução é desnecessária, por já serem escritas as obras em português.

Quanto ao segundo motivo, faz-se necessário ressaltar que um dos diversos prejuízos da colonização foi a imposição de uma outra cultura e uma outra língua aos moçambicanos. 
Atualmente, a língua portuguesa é a oficial do país, mas não é a língua materna da maioria da sua população.

Um povo pode ter sua língua trasladada para longe de si, abolida, e uma outra língua imposta nas escolas; mas a menos que alguém ensine esse povo a sentir numa nova língua, ninguém conseguirá erradicar o idioma antigo, e ele reaparecerá na poesia, que é o veículo do sentimento.

(ELIOT, 1972, p. 30)

Assim, o "idioma antigo" vai transparecer não só na poesia, mas também na prosa, estando presente nas obras de Mia Couto que, mesmo escrevendo em língua portuguesa, mescla vocábulos africanos, resultando em uma subversão à língua do outro, do colonizador.

Ainda em relação à linguagem empregada pelo autor, temos a evocação de ditados populares, próprios do seu meio, como por exemplo: "se a agulha cai no poço muitos espreitam, mas poucos descem a buscá-la" (COUTO 4, p. 15); "A lua anda devagar mas atravessa o mundo" (COUTO 1, p. 175); "Homem que baba não morde" (COUTO 2, p. 32).

Como uma forma de resgate da cultura, além dos provérbios, há a presença de elementos peculiares de Moçambique, principalmente do meio rural, espaço onde a maioria das suas histórias são passadas. É necessário destacar, dentro desses elementos, o aparecimento constante de rituais, mitos, feitiços, alucinações, sonhos, ações sobrenaturais, entre outros, resultando no deslocamento da fronteira entre a realidade e o fantástico.

Mia Couto é perguntado sobre isso em várias entrevistas e, para o autor, essa fronteira "é uma outra e não obedece aos padrões da racionalidade europeia [...] Não é ficção aceitarse que um homem se converte em bicho. O fluir de identidades entre pessoas, bichos e árvores faz parte do imaginário rural" (ZARUR, 2011).

$\mathrm{O}$ escritor ainda ressalta que, no Brasil,

há uma separação mais visível entre uma realidade mais científica, racional, de outra, mais mágica e simbólica. Em Moçambique, a realidade é dominada pelo imaginário rural, porque os africanos, mesmo quando são católicos ou muçulmanos, têm também essa outra religião, que não tem nome, mas que define sentidos éticos na vida [...] A fronteira entre a ficção e a realidade é outra.

(PRADO, 2011)

Em outra entrevista, o autor explica essa relação e confirma a presença desta na sua obra:

É o que eu faço desde o primeiro livro que escrevi. Não poderia fazer outra coisa. Quando se fala de África, a realidade está sempre misturada com o fantástico. Não se trata de algo mágico ou religioso, mas de algo relativamente diferente: há toda uma cosmogonia, um modo de entender como os vários mundos que compõem um universo coexistem em harmonia.

(CORRENTE D'ESCRITAS, 2011) 
Deste modo, personagens como feiticeiros e espíritos, entre outras, vão aparecer nas narrativas de Mia Couto, representando essa outra forma de ver o mundo, vivida e perpetuada por ele e pelos seus conterrâneos.

As personagens têm extrema importância para o escritor, visto que diversas vezes ele assume que seu processo de criação começa por elas, e, dificilmente, por uma ideia.

Eu não sou tanto um construtor de narrativas, o que me agrada mais é construir personagens... depois eu vou inventando histórias para que essa personagem tenha sentido, compreende? Mas pra mim o que se acende, aquilo que se ilumina, são personagens, são pessoas.

(MAQUÊA, 2005, p. 216)

O autor confessa que, primeiro, é preciso apaixonar-se por uma personagem, e ela vai conduzir a sua história, porém, são muitas personagens que surgem, forçando-o a limitá-las, para poder partir para a escrita do enredo:

há tantos personagens que me batem à porta que a certa altura eu tenho de comandar, fechar a porta e me dizer: agora, eu sou o dono desta casa. Daí, parto para esse processo mais oficinal, que dá menos prazer porque naquele primeiro momento eu sou uma esponja, um escutador. Ninguém é escritor se não for, primeiro, um escutador e deixar permear-se do que ouve.

(PRADO, 2011)

Através de suas palavras, fica claro que Mia Couto aprecia criar personagens e não vê a escrita de seus textos como um processo simples nem transcendental, e, sim, como um trabalho.

Quando é questionado se ele relê seus livros depois de publicados, o autor nega e explica que é "por medo de não sair deles", já que

aqueles personagens viveram tanto tempo dentro de mim, dois, três anos, e tão intensamente [...] Como eu não tenho outro processo de escrita que não seja pelos personagens, se eu não me afastar deles, não seria possível escrever outras histórias.

(PRADO, 2011)

Assim, Mia Couto mantém uma relação intensa com suas personagens durante a escrita do livro, mas, após a publicação, esta ligação é rompida. O afastamento implica, então, não reler sua obra para não se reencontrar com as personagens, nem inserir a mesma personagem em outro livro, vivendo outra história, como alguns autores fazem.

Entretanto, suas narrativas vão trazer personagens com pontos em comum, sendo que elas, na maioria, "pertencem a esse universo rural, são quase sempre negros, que vivem em condições marginais e, portanto, estão abertos a olhar o mundo de outra maneira." (PRADO, 2011)

É claramente perceptível, durante a leitura, essa outra forma de ver o mundo de suas 
personagens, que se posicionam de forma crítica e poética. Como em uma das epígrafes de Um rio chamado tempo, uma casa chamada terra, na qual a personagem Tuzébio, um taberneiro, constata: "Eis a diferença: os que, antes, morriam de fome, passaram a morrer por falta de comida" (COUTO 1, p. 142). Denunciando que, tanto no colonialismo, quanto depois dele, a população continua a viver na miséria, antes devido aos colonizadores, agora pelos negros que assumiram e abusam do poder.

Outra personagem, Juca Sabão, também ganha voz em uma epígrafe, criticando o colonialismo e suas divisões e ocupações de terras: "Encheram a terra de fronteiras, carregaram o céu de bandeiras. Mas só há duas nações - a dos vivos e a dos mortos" (COUTO 1, p. 13).

$\mathrm{Ou}$, ainda, em Antes de nascer o mundo, quando o narrador-personagem Mwanito pergunta ao pai de que raça ele e o irmão eram, e este responde: “- Ninguém é de uma raça. As raças - disse ele - são fardas que vestimos" (COUTO 3, p. 13). E Mwanito pondera, “Talvez Silvestre tivesse razão. Mas eu aprendi, tarde demais, que essa farda se cola, às vezes, à alma dos homens" (COUTO 3, p. 13), refletindo sobre o preconceito.

Além de negros e mulatos, Mia Couto insere personagens europeus em suas obras, com o intuito de confrontar as distintas realidades que compõem o contexto moçambicano, pois é a partir da diferença do outro que se afirma a própria identidade. Essas personagens estrangeiras vão ser afetadas pela cultura e crenças africanas e acabam participando de eventos considerados, por elas, impossíveis, sobrenaturais.

O autor não costuma caracterizar suas personagens excessivamente, narrando poucas informações sobre elas. Tanto o perfil físico quanto o psicológico são traçados de maneira sutil, no que vai resultar em personagens verossímeis, pois, segundo Erico Verissimo,

um escritor não deve tolher as suas criaturas. [...] Acho que o romancista não deve traçar rigidamente a psicologia de suas personagens, sob pena de torná-las sem vida como estátuas de pedra mal lavrada. Um tipo tem uma série de características essenciais, tanto morais quanto físicas. Mas é através dos atos, das palavras e principalmente dos sentimentos que ele se vai revelando no decorrer da narrativa.

(VERISSIMO, p. 23)

E é justamente isso que Mia Couto nos proporciona ao escrever sua obra, uma vez que é através das falas, dos pensamentos, das ações e das reações diante os eventos dentro da narrativa que o leitor vai ter acesso ao perfil das personagens.

Os nomes das personagens também é uma forma empregada pelo escritor para indicar as características delas, e eles vêm repletos de significações. Para exemplificar, podemos pensar na personagem Ana Deusqueira (COUTO 4), linda e sensual, todos os homens a 
querem; no Curozero Muando (COUTO 1), que faz papel de um coveiro, ou seja, só enterra, não cura ninguém; no Mwanito (COUTO 3), que significa menino, por ser ainda uma criança e estar relacionado à inocência; no Tio Aproximado (COUTO 3), pois ele não era um irmão direto do pai de Mwanito; na Dordalma (COUTO 3), a mãe falecida, sugerindo sua vida sofrida, de dores e decepções.

Portanto, além das características mostradas no decorrer da narrativa, é também através do nome que o autor fornece importantes subsídios referentes às personagens, para que o leitor consiga projetar uma imagem completa delas.

As personagens vão figurar em diferentes enredos, no entanto, essas histórias vão girar em torno de um tema comum:

Eu acho que desde o meu primeiro livro há um tema que nunca me abandonou que é o tema da procura de identidades. Estas identidades que nós pensamos como sendo puras, isoladas e estáticas, não são nada disso e pelo contrário são dinâmicas.

(FELIPE, 2011)

Certamente, outros temas podem ser extraídos de seus livros, mas a afirmação identitária, como relatou o próprio autor, é um elemento comum que, juntamente com a guerra, vai aparecer ora mais implícito em determinadas narrativas, ora mais explícito.

Para Piglia, "a literatura trabalha com os limites da linguagem, é uma arte do implícito", visto que "a ficção consiste tanto no que se narra como no que se cala" (1994, p. 84). Podemos aproximar esta afirmação de Piglia às literaturas africanas, pensando nos vários momentos de "silêncio" que permeiam as obras de Mia Couto, os quais denunciam a difícil realidade vivida pelos seus conterrâneos.

O não dito do texto torna-se tão importante quanto o dito, e a linguagem vai ser o artifício utilizado pelo escritor, seja para revelar, seja para ocultar:

o justo emprego da linguagem é, para mim, aquele que permite o aproximar-se das coisas (presentes ou ausentes) com discrição, cautela, respeitando o que as coisas (presentes ou ausentes) comunicam sem o recurso das palavras.

(CALVINO, 2010, p. 90-91)

Assim, Mia Couto aborda o cotidiano vivido por Moçambique como ex-colônia, fazendo críticas e expondo questões tão doloridas para o seu povo, amenizando isso através da linguagem, pois a "palavra associa o traço visível à coisa invisível, à coisa ausente, à coisa desejada ou temida, como uma frágil passarela improvisada sobre o abismo" (CALVINO, 2010, p. 90).

Devido ao processo de colonização, as produções literárias dos países africanos se limitaram, durante muito tempo, aos registros de descobrimentos - relatos feitos por 
navegadores - ou à literatura colonial - representação das vivências dos portugueses no alémmar -, enquanto que as literaturas africanas, predominantemente orais, ficavam à margem.

Só recentemente essas literaturas estão ganhando maior visibilidade, já que, ao invés do papel de meras vítimas, os africanos estão buscando seu lugar na enunciação, não sendo mais apenas objetos dela como era antes, e, sim, sujeito e objeto do discurso.

Mia Couto afirma possuir um projeto de moçambicanidade, deste modo, produz uma literatura engajada, com o objetivo de construir uma identidade nacional, consciente de que “fazer uma nação e fazer uma literatura são processos simultâneos” (MIRANDA, 1994, p. 33).

$\mathrm{O}$ autor inclui vários elementos culturais de Moçambique nas suas obras, permitindo aos leitores o contato com uma cultura vasta e rica que, tendo sido reprimida, correu o risco de cair no esquecimento. Ao invés da visão distorcida que o europeu nos oferecia das desconhecidas culturas africanas, este autor busca nos apresentar a realidade moçambicana, oferecendo-nos uma visão diferente e que viabiliza olhar o outro respeitando seus valores culturais.

É com a mistura de formas linguísticas e de temas que o escritor, consciente de que "é o sujeito que, pelo movimento de sua enunciação, dá sentido ao mundo" (DELAS, 1997, p. 170), consegue disseminar o seu projeto de moçambicanidade. Afinal, como afirma J. Tutikian, "por um lado, o trabalho de subversão da linguagem resulta na sua poetização, por outro, representa resistência ao processo colonizador" (2006, p. 59).

Neste sentido, Mia Couto é um autor exemplar quando se trata de demonstrar que a literatura desempenha um papel fundamental na busca pela construção da identidade nacional, já que em suas obras ele "desconstrói a realidade colonial lingüisticamente, denunciando-a tematicamente" (TUTIKIAN, 2006, p. 85).

É válido evocar uma de suas falas, na qual elucida este poder da literatura:

Creio que a literatura é exatamente isso: levar a que a história case com a História. A apetência em escutar e contar histórias está dentro de nós. Eu seria uma pessoa pobre se não fosse capaz de produzir histórias, de fazer da minha própria vida uma narrativa que posso emendar, apagar e enfeitar.

(ZARUR, 2011)

O processo criativo de Mia Couto envolve não só as personagens, a poesia, o uso inovador da língua, os provérbios, os elementos naturais e sobrenaturais de Moçambique, mas também todo o contexto colonial e pós-colonial do país, os quais estão intrínsecos ao escritor, por ele ter vivido e ainda viver este processo de construção identitária.

Assim, Mia Couto emenda, apaga e enfeita a sua vida, como também a vida de uma 
nação inteira, através literatura.

\section{Referências}

ABDALA JUNIOR, Benjamin. Literatura, história e política: literaturas de língua portuguesa no século XX. São Paulo: Ateliê Editorial, 2007.

CALVINO, Italo. Seis propostas para o próximo milênio. São Paulo: Companhia das Letras, 2010.

CORRENTE D'ESCRITAS. Entrevista a Mia Couto. Disponível em: <http://www.cmpvarzim.pt/povoa-cultural/pelouro-cultural/areas-de-accao/correntes-d-escritas/edicoesanteriores/correntes-d-escritas-2008/entrevistas-aos-escritores/entrevista-a-mia-couto〉. Acesso em: 19 de maio de 2011.

COUTO, Mia. Um rio chamado tempo, uma casa chamada terra. São Paulo: Companhia das Letras, 2003.

Venenos de Deus, remédios do diabo: as incuráveis vidas de Vila Cacimba. São Paulo: Companhia das Letras, 2008.

. Antes de nascer o mundo. São Paulo: Companhia das Letras, 2009.

O último voo do flamingo. São Paulo: Companhia das Letras, 2005.

Vinte e zinco. Lisboa: Caminho, 1999.

Terra sonâmbula. São Paulo: Companhia das Letras, 2007.

Na berma de nenhuma estrada. Lisboa: Caminho, 2001.

DELAS, Daniel. Introdução a uma poética das escrituras mestiças. In: BERND, Zilá; UTÉZA, Francis (Orgs.). Produção literária e identidades culturais: estudos de literatura comparada. Porto Alegre: Sagra Luzzatto, 1997. p. 165-175.

DORIGATTI, Bruno. Entrevista com Mia Couto. Disponível em: <http://www.literal.com.br/artigos/mia-couto>. Acesso em: 12 de maio de 2011.

ELLIOT, T.S. A função social da poesia. In: A essência da poesia. Trad. Maria Luiza Nogueira. Rio de Janeiro: Artenova, 1972.

FELIPE, Gil. Entrevista Mia Couto. Disponível em: <http://www.revistabula.com/posts/entrevistas/entrevista-mia-couto>. Acesso em: 13 de maio de 2011.

MAQUÊA, Vera. Entrevista com Mia Couto. Via Atlântica, São Paulo, nº 8, páginas 205 - 217, dezembro de 2005.

MIRANDA, Wander Melo. Nações literárias. Revista Brasileira de Literatura Comparada, São Paulo, n. 2, p. 31-38, maio 1994.

PADILHA, Laura Cavalcante. Novos pactos, outras ficções: ensaios sobre literaturas afro-lusobrasileiras. Porto Alegre: EDIPUCRS, 2002.

PIGLIA, Ricardo. O laboratório do escritor. São Paulo: Iluminuras, 1994. 
PRADO, Ricardo. Personagem em busca de um autor. Disponível em: <http://www.cartacapital.com.br/carta-na-escola/personagem-em-busca-de-um-autor>. Acesso em: 13 de maio de 2011.

TUTIKIAN, Jane. Velhas identidades novas: o pós-colonialismo e a emergência das nações de língua portuguesa. Porto Alegre: Sagra Luzzatto, 2006.

VERISSIMO, Erico. Romance de um romance.

ZARUR, Cristina. O prazer quase sensual de contar histórias. O Globo, Rio de Janeiro, 30 de junho de 2007, Prosa \& Verso, pág. 6. Disponível em: <http://flip2007.wordpress.com/2007/06/30/oprazer-quase-sensual-de-contar-historias-entrevista-com-mia-couto/>. Acesso em: 19 de maio de 2011. 